\title{
Adherence to antimalarial drug policy among doctors in Delta State, Nigeria: impli- cations for malaria control
}

\author{
Irikefe P. Obiebi
}

Ghana Med J 2019; 53(2): 109-116 doi:http://dx.doi.org/10.4314/gmj.v53i2.5

\author{
Department of Community Medicine, Delta State University Teaching Hospital, Oghara
}

Corresponding author: Dr. Irikefe P. Obiebi

E-mail: irikefewhite@yahoo.com

Conflict of interest: None declared

\section{SUMMARY}

Background: Malaria is a public health problem compounded with a widespread emergence of drug-resistant Plasmodium falciparum which necessitated the formulation of a new antimalarial drug policy (AMP).

Objective: This study was designed to assess adherence to the policy among physicians in health facilities in Delta state, Nigeria.

Design: Cross-sectional, analytic study. Data were collected with a semi-structured questionnaire.

Setting: Two secondary and one tertiary health facilities in Delta State, Nigeria

Participants: Physicians selected with a simple random technique from the facilities

Main outcome measures: Prescribing pattern of antimalarial drugs and adherence to WHO treatment guideline among doctors.

Results: Majority (90.8\%) of respondents believed the antimalarial policy (AMP) should be strictly adhered to, although three-fifth $(61.0 \%)$ of them rated its performance as poor. The level of adherence to the national antimalarial drug policy was high $(78.5 \%)$ as most doctors prescribed Arthemeter-Lumefantrine, AL for uncomplicated malaria however barely two-fifth (35.4\%) adhered to prescribing injectable Artesunate for complicated malaria. AL, (71.9\%) was the most prescribed antimalarial drug for uncomplicated malaria The most prescribed antimalarial drugs for complicated malaria was artesunate (40.0\%) followed by quinine (27.6\%) and artemether (26.7\%); although, chloroquine was also prescribed.

Conclusion: The level of adherence to AMP among doctors was sub-optimal. Continuous education of doctors on the new AMP is needed to achieve malarial control.

Keywords: Adherence, antimalarial, drug policy, resistance, guidelines

Funding: No funding was received for this study

\section{INTRODUCTION}

Malaria is a major public health problem in Nigeria where it accounts for more deaths than in any other country in the world. It is believed to be the most reported disease condition among patients attending health facilities. Every year, Nigeria accounts for almost a quarter of all malaria-related deaths in Africa. Nationally, Malaria affects about 100 million people every year and constitutes three-fifth of outpatient department attendance. ${ }^{1-4}$ The immense burden from this scourge of humanity extends beyond the imaginable to economic loss entwined as inextricable direct and indirect costs valued at many billion dollars in Africa. ${ }^{5}$ Pregnant women and their babies are not spared from this menace at all, as malaria constitutes a major cause of unintended pregnancy loss and maternal deaths annually.
Also, the number of infants in sub-Saharan Africa dying annually as a result of malaria infection during pregnancy ranges up to hundreds of thousands. ${ }^{6,7}$ On the other hand, with a meagre percentage of children with malaria receiving Artemisinin-based combination therapy the prospect of malaria control in Nigeria is one that is overcast and overlaid with uncertainty, and eliminating the disease from Africa even becomes more intricate. ${ }^{8,9}$

Plasmodium falciparum, one of the parasites that cause malaria have become increasingly resistant to chloroquine, which was once the most widely used anti-malarial drug. ${ }^{10,11}$ Presently, the world contends with the resurgence of malaria due partly to the spread of strains of the parasite that are resistant to chloroquine and other antimalaria medicines. ${ }^{9,10}$ 
This widespread emergence of drug-resistant strains of Plasmodium falciparum has necessitated an improvement in measures to combat this major drawback to malaria control. For this reason, a new antimalarial drug policy formulated by the World Health Organization and adopted by member nations has come to light.
Nigeria has changed its treatment policy for management of malaria and now uses Artemisinin-based combination therapy (ACT) in treating uncomplicated malaria and Quinine for the management of severe or complicated malaria. As such, the effective treatment for uncomplicated malaria is artemisinin such as Artesunate or Artemether combined with another anti-malarial drug (Table 1). ${ }^{12}$

Table 1 New guidelines for prescribing antimalarial drugs and their dosage regime ${ }^{11}$

\begin{tabular}{|c|c|c|c|}
\hline Drugs for uncomplicated malaria & $\begin{array}{l}\text { Route of admin- } \\
\text { istration }\end{array}$ & Strength/dosage & Frequency and Duration \\
\hline $\begin{array}{l}\text { Artemether plus Lumefantrine (first line } \\
\text { drug) }\end{array}$ & Oral (Tablet) & $\begin{array}{l}20 \mathrm{mg} \text { artemether }+120 \mathrm{mg} \\
\text { lumefantrine per tablet }\end{array}$ & $\begin{array}{l}\text { four tablets twice daily for three } \\
\text { days }\end{array}$ \\
\hline $\begin{array}{l}\text { Artesunate }+ \text { mefloquine (alternatives/sec- } \\
\text { ond line) }\end{array}$ & Oral (Tablet) & $\begin{array}{l}\text { Artesunate } 4 \mathrm{mg} / \mathrm{kg} / \text { Mefloquine } 15 \text { - } \\
25 \mathrm{mg} / \mathrm{kg}\end{array}$ & twice daily for three days \\
\hline Artesunate (first choice) & $\begin{array}{l}\text { Intravenous/intra- } \\
\text { muscular }\end{array}$ & $2-4 \mathrm{mg} / \mathrm{kg}$ & $\begin{array}{l}12 \text { hourly until the patient is } \\
\text { well enough for oral medication }\end{array}$ \\
\hline Quinine (second choice) & $\begin{array}{l}\text { Intravenous (in intra- } \\
\text { venous fluid) }\end{array}$ & $10-20 \mathrm{mg} / \mathrm{kg}$ & $\begin{array}{l}8-12 \text { hourly until the patient is } \\
\text { well enough for oral medication }\end{array}$ \\
\hline $\begin{array}{l}\text { Mono-therapy is not recommended for un- } \\
\text { complicated malaria }\end{array}$ & & & \\
\hline
\end{tabular}

Adapted from National Antimalarial Treatment Policy, Federal Ministry of Health, Abuja-Nigeria ${ }^{12}$. In Nigeria, much information on adherence to the antimalarial policy is not available nor has much attention been paid to appropriate dosages and duration of completing a full course of prescribed doses. In some of the countries, studies in this regard, show that adherence is poor ${ }^{13-15}$, and some studies have linked the poor adherence to increase in malaria-related morbidity and mortality, with therapeutic failure, drug resistance and increased drug costs as underlying factors. ${ }^{13,16}$ Given the challenges above, the study was undertaken to assess the level of adherence to the anti-malarial drug policy.

It presupposes that the message in the policy had permeated everywhere in the health sector reaching the prescribers as well as the suppliers, with an expectant absolute adherence to the policy. However, in reality, it is not so, in that some prescribers still resort to monotherapy for the treating of malaria. ${ }^{17}$ Therefore, there was a need to assess the level of compliance with the anti-malarial policy by the prescribers in the treatment of malaria. The results of this study could provide policymakers and stakeholders with evidence for improved management of malaria in this era of drug resistance and guide the procurement of anti-malarial drugs that are frequently prescribed and, in their preferred dosage forms.

\section{METHODS}

\section{Study area, design, and population}

This cross-sectional analytic study included two hundred and sixty doctors (medical officers, resident doctors, and consultants) of different cadres selected from two secondary and one tertiary health facilities in Delta state with a simple random technique. It excluded medical interns.

\section{Data collection and analysis}

Data were collected with a semi-structured self-administered questionnaire, analysed with SPSS version 22, and expressed as frequencies with percentages. Level of adherence was defined by the proportion of respondents whose prescription patterns conformed with the antimalarial drugs, dosage regimens, frequency and duration stipulated in the national antimalarial treatment guidelines particularly concerning the first drug of choice for complicated and uncomplicated malaria. ${ }^{12} \mathrm{~A}$ hundred percent $(100 \%)$ compliance among prescribers is accepted as adequate. Association between cadres of prescribers and level of adherence was elicited with chisquare test and the significance level was set at $\mathrm{p}<0.05$.

\section{Ethical consideration}

The ethical review board of Delta State University Teaching Hospital gave ethical clearance for this study. The reference number of the ethical approval is DELSUTH/HREC/2016/002. 


\section{RESULTS}

About half (48.8\%) of the study participants were in the age range 31-40 and, with more males than females, male to female ratio was approximately 3:2. Most respondents were medical officers while 6-10 years was the predominant period of practice. Awareness of antimalarial policy (AMP) was almost absolute, and the majority (90.8\%) of doctors in this study believed the AMP should be strictly adhered to, although three-fifth $(61.0 \%)$ of them rated its performance as poor.

Table 2 Socio-demographic and Other Characteristics among Respondents

\begin{tabular}{|c|c|c|}
\hline Variables & Categories & $\begin{array}{l}\text { Frequency } \\
(\%)\end{array}$ \\
\hline \multirow[t]{4}{*}{ Age group } & $21-30$ & $101(38.8)$ \\
\hline & $31-40$ & $127(48.8)$ \\
\hline & $41-50$ & $27(10.4)$ \\
\hline & $51-60$ & $5(1.9)$ \\
\hline \multirow[t]{2}{*}{ Sex } & Male & $153(60.2)$ \\
\hline & Female & $108(39.8)$ \\
\hline \multirow[t]{4}{*}{ Designation } & Medical officer & $122(46.6)$ \\
\hline & Registrar & $85(32.8)$ \\
\hline & Senior Registrar & $44(17.0)$ \\
\hline & Consultant & $8(3.1)$ \\
\hline \multirow[t]{5}{*}{ Years of experience } & $1-5$ & $96(36.9)$ \\
\hline & $6-10$ & $119(45.8)$ \\
\hline & $11-15$ & $24(9.2)$ \\
\hline & $16-20$ & $17(6.5)$ \\
\hline & $21-25$ & $4(1.6)$ \\
\hline \multirow[t]{2}{*}{ Awareness of AMP } & Yes & $246(94.6)$ \\
\hline & No & $14(5.4)$ \\
\hline \multirow[t]{3}{*}{ Assessment of AMP } & Good & $10(9.9)$ \\
\hline & Fair & $78(30.1)$ \\
\hline & Poor & $158(61.0)$ \\
\hline \multirow[t]{2}{*}{ Strict adherence } & Yes & $238(90.8)$ \\
\hline & No & $22(9.2)$ \\
\hline \multirow{2}{*}{$\begin{array}{l}\text { Have reasons for Prescrib- } \\
\text { ing drugs }\end{array}$} & Yes & $241(92.7)$ \\
\hline & No & $19(6.3)$ \\
\hline \multirow[t]{9}{*}{ Reasons for adherence* } & Cost-effective & $131(26.6)$ \\
\hline & Better adherence & $68(13.8)$ \\
\hline & Less Resistance & $56(11.4)$ \\
\hline & Less Side-effects & $25(5.1)$ \\
\hline & Rapid Clearance & $20(4.1)$ \\
\hline & Better tolerated & $11(2.2)$ \\
\hline & Effective & $171(34.8)$ \\
\hline & Readily available & $5(1.0)$ \\
\hline & Easy to prescribe & $5(1.0)$ \\
\hline \multirow[t]{3}{*}{ Reason for not adhering } & Expensive & $7(31.8)$ \\
\hline & Poor/No clinical response & $10(45.5)$ \\
\hline & $\begin{array}{l}\text { Patients' complaints } \\
\text { about too many tablets to } \\
\text { swallow }\end{array}$ & $5(22.7)$ \\
\hline
\end{tabular}

*Multiple responses apply
About a quarter $(26.6 \%)$ think that antimalarial drug policy creates an avenue for getting affordable drugs while over a third agree the policy provides a platform for efficient use of antimalarial drugs (Table 2).

The overall level of adherence for prescribing Artemether-Lumefantrine (AL) for uncomplicated malaria was 204/260 (78.5\%) while that for prescribing injectable Artesunate for complicated malaria was 92/260 (35.4\%). Adherence to AL did not vary significantly among different categories of prescribers with the lowest among consultants $(75 \%)$ and highest among medical officers $(81.2 \%) ; p=0.898$. Adherence to prescribing injectable artesunate was highest among senior registrars (70.5\%) but least among registrars $(17.6 \%) ; \mathrm{p}<0.001$ (Table 3).

Level of adherence was based on the first drug of choice for complicated and uncomplicated malaria; SP: sulphadoxine-pyrimethamine; *LR-chi-square ArthemeterLumefantrine, $(71.9 \%)$ was the most prescribed antimalarial drug for uncomplicated malaria. The most prescribed antimalarial drugs for complicated malaria was artesunate $(40.0 \%)$ followed by quinine $(27.6 \%)$ and artemether (26.7\%) (Table 4).

Most (86.6\%) prescriptions of intramuscular artemether came as $2.4 \mathrm{mg} / \mathrm{kg}$ for the first choice though in $70.4 \%$ of cases it was also prescribed as $3.2 \mathrm{mg} / \mathrm{kg}$ as the second choice. Intravenous artesunate was administered at $2.4 \mathrm{mg} / \mathrm{kg}$ as the first choice in $63.3 \%$ of occasions.

Intravenous quinine as a first choice was administered at $20 \mathrm{mg} / \mathrm{kg}$ for most $(80.6 \%)$ cases while in very few $(6.5 \%)$ occasions at $10 \mathrm{mg} / \mathrm{kg}$. In this study, some physicians administered or prescribed oral quinine in adult and paediatric doses. Some prescribers administered intramuscular chloroquine (Table 5).

Artesunate, the most prescribed antimalarial drug for complicated malaria, and artemether were prescribed for three days by $56.3 \%$ and $67.9 \%$ of the doctors who responded. Majority of the physicians who prescribed quinine did so for two days. Artemether-amodiaquine and artemether-lumefantrine were both prescribed for three days (Table 6).

Some respondents (9 out of 15) prescribed Arthemeterlumefantrine as the first drug of choice for uncomplicated malaria for three days. Others also prescribed chloroquine only for three days. SP was given for one day, but a minority also prescribed it for three days (Table 6). Majority of the responses indicate that oral Artemether-lumefantrine was prescribed as 120/80mg dose and Chloroquine as a $600 \mathrm{mg}$ dose. 
Table 3 Level of adherence to national antimalarial drug policy among prescribers

\begin{tabular}{|c|c|c|c|c|c|c|}
\hline Variables & $\begin{array}{l}\text { Adherence } \\
(\mathbf{N}=\mathbf{2 6 0})\end{array}$ & $\begin{array}{l}\text { Medical officer } \\
(\mathrm{n}=122)\end{array}$ & $\begin{array}{l}\text { Registrar } \\
(\mathrm{n}=\mathbf{8 5})\end{array}$ & $\begin{array}{l}\text { Senior Regis- } \\
\operatorname{trar}(n=44)\end{array}$ & Consultant $(n=8)$ & $P$ value \\
\hline \multirow[t]{2}{*}{$\begin{array}{l}\text { Artemether-Lumefan- } \\
\text { trine }(20 / 120)\end{array}$} & Yes (204) & $94(77.0)$ & $69(81.2)$ & $35(79.5)$ & $6(75.0)$ & \multirow[t]{2}{*}{0.898} \\
\hline & No (56) & $28(23.0)$ & $16(19.8)$ & $9(20.5)$ & $2(25.0)$ & \\
\hline \multirow[t]{2}{*}{$\begin{array}{l}\text { Artemether-amodia- } \\
\text { quine }\end{array}$} & Yes (62) & $22(18.0)$ & $11(12.9)$ & $24(54.5)$ & $5(62.5)$ & \multirow[t]{2}{*}{$<0.001$} \\
\hline & No (198) & $100(82.0)$ & $74(87.1)$ & $20(45.5)$ & $3937.5)$ & \\
\hline \multirow[t]{2}{*}{ Artemether-SP } & Yes (4) & $0(0.0)$ & $1(1.2)$ & $3(6.8)$ & $0(0.0)$ & \multirow{4}{*}{$\begin{array}{l}\mathbf{0 . 0 3 6}^{*} \\
<0.001\end{array}$} \\
\hline & No (256) & $122(100.0)$ & $84(98.8)$ & $41(93.2)$ & $8(100.0)$ & \\
\hline \multirow[t]{2}{*}{ Injection Artesunate } & Yes (92) & $43(35.2)$ & $15(17.6)$ & $31(70.5)$ & $3(37.5)$ & \\
\hline & No (168) & $79(64.8)$ & $70(82.4)$ & $13(29.5)$ & $5(62.5)$ & \\
\hline \multirow[t]{2}{*}{ Intravenous quinine } & Yes (125) & $59(48.4)$ & $23(27.1)$ & $40(90.9)$ & $2(25.0)$ & \multirow[b]{2}{*}{$<0.001^{*}$} \\
\hline & No (135) & $63(51.6)$ & $62(72.9)$ & $4(9.1)$ & $6(75.0)$ & \\
\hline
\end{tabular}

Table 4 Types of Antimalarial Prescribed

\begin{tabular}{|c|c|c|c|}
\hline \multirow[t]{2}{*}{ Variables } & \multirow[t]{2}{*}{ Categories } & \multicolumn{2}{|c|}{ Frequency (\%) } \\
\hline & & First Choice & Second Choice \\
\hline \multirow{5}{*}{$\begin{array}{l}\text { Medicines Prescribed for Compli- } \\
\text { cated Malaria }\end{array}$} & Chloroquine & $3(1.3)$ & $2(1.2)$ \\
\hline & Quinine & $62(27.6)$ & $60(35.0)$ \\
\hline & Amodiaquine & $10(4.4)$ & $1(0.6)$ \\
\hline & Artesunate & $90(40.0)$ & $79(46.2)$ \\
\hline & Arthemether & $60(26.7)$ & $29(17.0)$ \\
\hline \multirow{7}{*}{$\begin{array}{l}\text { Drugs Prescribed for Uncompli- } \\
\text { cated Malaria }\end{array}$} & Arthemeter-amodiaquine & $2(6.3)$ & $5(15.6)$ \\
\hline & Arthemeter-lumefantrine & $23(71.9)$ & $6(18.8)$ \\
\hline & Dihydroartemisinin-piperaquine & $3(9.4)$ & $2(6.2)$ \\
\hline & Artesunate & $4(12.6)$ & $0(0.0)$ \\
\hline & Arthemeter-sulphadoxine/Pyremethamine & $0(0.0)$ & $1(3.1)$ \\
\hline & Sulphadoxine -pyremethamine & $0(0.0)$ & $8(25.0)$ \\
\hline & Chloroquine & $0(0.0)$ & $10(31.3)$ \\
\hline
\end{tabular}

Table 5 Dosages of Drugs Prescribed or administered for complicated malaria

\begin{tabular}{|c|c|c|c|c|}
\hline Variables & ROA & Dosage & First choice & Second choice \\
\hline \multirow[t]{6}{*}{ Arthemeter } & I.M & $2.4 \mathrm{mg} / \mathrm{kg}$ & $52(86.6)$ & $7(25.9)$ \\
\hline & & $3.2 \mathrm{mg} / \mathrm{kg}$ & $5(8.3)$ & $19(70.4)$ \\
\hline & & $1.6 \mathrm{mg} / \mathrm{kg}$ & $1(1.7)$ & \\
\hline & & $80 \mathrm{mg}$ & 1(1.7) & \\
\hline & & $150 \mathrm{mg}$ & $1(1.7)$ & \\
\hline & & $20 \mathrm{mg} / \mathrm{kg}$ & & $1(3.7)$ \\
\hline \multirow[t]{6}{*}{ Artesunate } & IV & $2.4 \mathrm{mg} / \mathrm{kg}$ & $57(63.3)$ & $42(69.8)$ \\
\hline & & $3 \mathrm{mg} / \mathrm{kg}$ & $20(22.2)$ & $17(27.9)$ \\
\hline & & $30 \mathrm{mg}$ & $1(1.1)$ & \\
\hline & & $3.2 \mathrm{mg} / \mathrm{kg}$ & $11(12.3)$ & $1(1.6)$ \\
\hline & & $1.2 \mathrm{mg} / \mathrm{kg}$ & $1(1.1)$ & \\
\hline & & $2 \mathrm{mg} / \mathrm{kg}$ & & $1(1.6)$ \\
\hline \multirow[t]{6}{*}{ Quinine } & IV & $20 \mathrm{mg} / \mathrm{kg}$ & $50(80.6)$ & 57 (91.9) \\
\hline & IV & $10 \mathrm{mg} / \mathrm{kg}$ & $4(6.5)$ & $1(1.6)$ \\
\hline & Oral & $600 \mathrm{mg}$ & $6(9.7)$ & \\
\hline & Oral & $300 \mathrm{mg}$ & $2(3.2)$ & \\
\hline & & $60 \mathrm{mg}$ & & $3(4.9)$ \\
\hline & & $2.4 \mathrm{mg} / \mathrm{kg}$ & & $1(1.6)$ \\
\hline Amodiaquine & Oral & $2.4 \mathrm{mg} / \mathrm{kg}$ & $10(100.0)$ & \\
\hline Artemether-Lumefantrine & Oral & $20 \mathrm{mg}+120 \mathrm{mg}$ & $3(100.0)$ & \\
\hline Artesunate - amodiaquine & Oral & $\begin{array}{l}10 \mathrm{mg} / \mathrm{kg} \\
4 \mathrm{mg} / \mathrm{kg}\end{array}$ & $13(100)$ & \\
\hline Chloroquine & I.M & $25 \mathrm{mg} / \mathrm{kg}$ & & $10(100)$ \\
\hline \multirow[t]{3}{*}{ Artemether } & & $3.2 \mathrm{mg} / \mathrm{kg}$ & & $19(70.4)$ \\
\hline & & $2.4 \mathrm{mg} / \mathrm{kg}$ & & $7(25.9)$ \\
\hline & & $20 \mathrm{mg} / \mathrm{kg}$ & & $1(3.7)$ \\
\hline
\end{tabular}

ROA: route of administration; I.M: intramuscular; IV: intravenous 
Table 6 Duration of Administration of Drug for Complicated malaria

\begin{tabular}{|c|c|c|c|c|c|c|c|}
\hline \multirow[t]{3}{*}{ Variables } & \multicolumn{7}{|c|}{ Duration in days } \\
\hline & \multicolumn{7}{|c|}{ Frequency (\%) } \\
\hline & One & Two & Three & Four & Five & Seven & Total \\
\hline Artemether & $9(15.0)$ & $2(3.3)$ & 49 (81.7) & $0(0.0)$ & $0(0.0)$ & $0(0.0)$ & $60(100)$ \\
\hline Artesunate & $23(25.0)$ & $15(16.3)$ & $50(54.3)$ & $2(20.0)$ & $1(1.1)$ & $1(1.1)$ & $92(100)$ \\
\hline Quinine & $5(8.1)$ & $42(67.7)$ & $7(11.3)$ & $0(0.0)$ & 1 (1.6) & $711.3)$ & $62(100)$ \\
\hline Amodiaquine & $0(0.0)$ & $0(0.0)$ & $10(100)$ & $0(0.0)$ & $0(0.0)$ & $0(0.0)$ & $10(100)$ \\
\hline ART-LUM & $0(0.0)$ & $0(0.0)$ & $4100.0)$ & $0(0.0)$ & $0(0.0)$ & $0(0.0)$ & $4(100)$ \\
\hline ART-AMO & $11(80.0)$ & $0(0.0)$ & $2(20.0)$ & $0(0.0)$ & $0(0.0)$ & $0(0.0)$ & $13(100)$ \\
\hline Arthemeter & $0(0.0)$ & $5(17.9)$ & $19(67.9)$ & & $2(7.1)$ & $2(7.1)$ & $28(100)$ \\
\hline Artesunate & 19 (32.) & $32(55.2)$ & $4(6.9)$ & & $1(1.7)$ & $2(3.4)$ & $58(100)$ \\
\hline Quinine & $2(4.1)$ & $1734.7)$ & $19(38.8)$ & & $0(0.0)$ & $11(22.7)$ & $49(100)$ \\
\hline Amodaquine & $1(50.0)$ & $0(0.0)$ & $1(50.0)$ & & $0(0.0)$ & $0(0.0)$ & $2(100)$ \\
\hline
\end{tabular}

ART-LUM; Arthemeter-Lumefantrine; ART-AMO; Arthemeter-Amodiaquine.

Table 7 Duration of administration of uncomplicated malaria

\begin{tabular}{|c|c|c|c|c|c|}
\hline \multirow[t]{3}{*}{ Variable } & \multicolumn{5}{|c|}{ Duration in days } \\
\hline & \multicolumn{3}{|c|}{ Second choice, $\mathbf{n}(\%)$} & \multicolumn{2}{|c|}{ First choice, n(\%) } \\
\hline & One & Three & Five & Two & Three \\
\hline ART-LUM & $7(43.8)$ & $9(56.2)$ & $0(0.0)$ & $0(0.0)$ & $184(100.0)$ \\
\hline ART-AMO & $1(12.5)$ & $7(87.5)$ & $0(0.0)$ & $0(0.0)$ & $2(100.0)$ \\
\hline DHA-PPQ & $0(0.0)$ & $3(75.0)$ & $1(25.0)$ & $0(0.0)$ & $3(100.0)$ \\
\hline ART-SP & $0(0.0)$ & $0(0.0)$ & $1(100.0)$ & & \\
\hline ART & $0(0.0)$ & $0(0.0)$ & $2(100.0)$ & $1(25.0)$ & $3(75.0)$ \\
\hline SP & $23(0.0)$ & $3(100.0)$ & $26(0.0)$ & & \\
\hline CQ & $0(0.0)$ & $33(100.0)$ & $0(0.0)$ & & \\
\hline
\end{tabular}

ART-LUM; Arthemeter-Lumefantrine; ART-AMO; Arthemeter-Amodiaquine; SP: Sulphadoxine -pyrimethamine; DHA-PPQ: Dihydroartemisinin-piperaquine

\section{DISCUSSION}

This study focused on assessing the adherence of prescribers to the antimalarial drug policy in Nigeria.

Almost half the respondents in this study were in the age group 31-40 years. This observation is not unexpected as most of the workforce, including those in the health sector comprises young people and those in their middleages. The finding that majority of the respondents had practised for 6-10 years gives credence to the assertion that the doctors in this study were mostly young people who had practised for a short time post-graduation. Furthermore, that a majority of respondents were medical officers is not unexpected because this study was conducted in a tertiary and two secondary centres where the bulk of the doctors are medical officers. As similarly found in a previous study conducted in Kenya, ${ }^{18}$ the level of awareness of the national antimalarial drug policy among the physicians in this study was high, however, more than half of them rated the policy as poor.
Furthermore, only less than one-tenth of the doctors reported not adhering strictly to the policy in prescribing antimalarial drugs, and their reasons included but were not limited to, high cost, and poor clinical response to treatment. High cost, to about the same degree, also deterred health workers from prescribing ACTs in a previous study ${ }^{17}$, where probably similar patients with low socio-economic indices constituted the majority of those seen at the health facilities. Those who reported strict adherence opined that the antimalarial drug policy facilitates better adherence. In the same way reports from Malawi and Tanzania indicate that a more significant percentage of patients were completely adherent to artemisinin-based combination therapy. ${ }^{12,13}$

The level of adherence to the national antimalarial drug policy was high among the prescribers in this study as the majority (78.5\%) prescribed AL for uncomplicated malaria however less than two-fifths $(35.4 \%)$ adhered to 


\section{Original Article}

prescribing injectable Artesunate for complicated malaria.

This level of compliance to the national antimalarial drug prescription falls short of hundred per cent expected of doctors who are usually at the helm of affairs in health facilities. Nonetheless, three-fifths of the doctors in this study appraised the antimalarial policy to be poor; this factor probably adversely affected their adherence. The adherence to AL prescription was not any difference between the cadres of prescribers, although a significantly higher proportion of senior registrars prescribed injectable Artesunate. This differential prescription of artesunate may be as a result of a relative lack of awareness and/or availability of the drug in the facilities where these physicians practised.

Some doctors demonstrated adherence to the antimalarial drug policy in that among the antimalarial drugs prescribed for uncomplicated malaria Arthemeter-Lumefantrine, (AL) was the most prescribed as first-line treatment. Although this finding differs from that in a previous study where mainly single antimalarial drugs were prescribed, second-line treatment with chloroquine was most commonly observed in this study and congruent with a finding from the previous study conducted in southeastern Nigeria where chloroquine was the most prescribed antimalarial drug. ${ }^{17}$ The effectiveness of Arthemeter-Lumefantrine in the treatment of malaria has been revalidated severally, ${ }^{20}$ thus the finding in this study about prescribing ACT may provide a basis to exercise optimism in the control of malaria in the region. This seeming compliance with the antimalarial drug policy nonetheless, single prescription of chloroquine, artesunate and Sulphadoxine-pyrimethamine as recorded in this study depicts monotherapy and a certain level of noncompliance. Similarly, another study conducted in Ghana also corroborates the non-adherence with the antimalarial policy. ${ }^{21}$

Adherence to the AMP policy is further exemplified in artesunate being the most frequently prescribed antimalarial drug of the first choice for complicated malaria in this study. And, that at almost all times, it was administered intravenously at $2 \mathrm{mg} / \mathrm{kg}$ for three days is commendable. The preceding is true as substantial and quick recovery with minimal or no complication is usually guaranteed if the right antimalarial drugs are administered via the appropriate route, especially in the critical hours of treatment of complicated malaria. ${ }^{22}$

Inversely, some prescribers also administered artemisinin-based combination therapy for complicated malaria in this study; an outcome which heralds a gap in the implementation of the antimalarial drugs policy and creates a shortage with far-reaching implications for the health of the public especially among under-five children who are the worst hit by malaria., ${ }^{3,23}$

In this study, chloroquine was also prescribed for complicated malaria mostly as a second choice. The above finding is not unconnected to the fact that people often fall back to the 'old drug that once did the magic' for them after being disappointed by the many "double strength six-dose regimen" of antimalarial drugs produced by numerous pharmaceutical companies emerging from within and outside the country. ${ }^{14,16}$

In this era, many people often claim chloroquine is effective even where evidence for resistance exists; ${ }^{10,11}$ most likely because some of the artemisinin-based combination drugs they have taken were substandard. ${ }^{24,25}$ All the more so, in settings where available antimalarial drugs are known to be efficacious the unresolved puzzle of poor adherence persists. ${ }^{26,27}$ Thus, the emergence of resistance by malarial parasites to antimalarial drugs would not solely be due to irrational drug use even though prescribing antimalarial drugs at the wrong or sub-optimal doses ("underdosing") also significantly affect the clearance of the parasite from the bloodstream and create ample opportunity for the parasites to develop resistance. ${ }^{11}$ Nonetheless, the different doses of antimalarial drugs prescribed in this study differ from those stipulated in the treatment guidelines and could act as contributing factors to the emerging problem of resistance. Rapidly eliminated drugs, such as artesunate (monotherapy) and quinine, should be given over longer periods to ensure therapeutic efficacy. Nonetheless, prescribing quinine, artesunate, and artemether for seven days as recorded in this study could compound the challenges with a therapeutic clearance of malarial parasitaemia and eventually, malaria control. This is because poor adherence with drugs taken for extended periods has been observed among patients; ${ }^{3,28}$ consequently, it is advisable to adhere to combined antimalarial drugs taken for fewer days in order to encourage compliance with completing a full course of treatment in record time.

Adherence to anti-malarial drug policy can bring about a reduction in malaria burden though antimalarial drug alone will not have a sustainable impact in reducing the burden of the disease. ${ }^{29}$ The level of adherence in this study can be improved on with intensified efforts to increase awareness on the need to adhere strictly to the AMP. Continuous medical education of physicians should include antimalarial drug policy and, professional associations and other allied medical bodies such as the medical and dental council of Nigeria can be involved to support and advocate adherence to the current malarial treatment guideline. 


\section{CONCLUSION}

Prescribers in this study not only have confidence in but also adhered to the antimalarial drug policy. However, a few prescribers did not comply with the national treatment guidelines. The level of adherence was as low as $35.4 \%$ and as high as $78.5 \%$ respectively for complicated and uncomplicated malaria. This could have a significant impact on the evolving resistance to antimalarial drugs as well as the control of malaria in the region.

\section{REFERENCES}

1. World Health Organization. World Malaria Report 2017. Geneva, Switzerland: World Health Organization; 2017:40-49

2. World Health Organization. World Malaria Report. Vol.2030. World Health Organization; 2016: xii xvii

3. Elechi HA, Rabasa AI, Muhammad FB, Garba MA, Abubabak GF, Umoru MA. Prevalence and pattern of malaria parasitaemia among under-five febrile children attending paediatric out-patient clinic at University of Maiduguri Teaching Hospital, Maiduguri. Niger J Paed. 2015;42(4):319-24.

4. United Nations Children's Fund. Malaria: A Major Child Death and Poverty in Africa [Internet]. New York, USA; 2014 [cited 2018 Jul 24]. Available from https://www.unicef.org.

5. Centres for Disease Control and Prevention (CDC). Impact of malaria [Internet]. 2016 [cited 2017 Oct 3]. Available from: https://www.cdc.gov/malaria/malaria_worldwide/i mpact.htm

6. Sigauque B, Sanz S, Ordi J, Aponte JJ, Mabunda S, Alonso PL, et al. Impact of Malaria at the End of Pregnancy on Infant Mortality and Morbidity. $J$ Infect Dis. 2011;203:691-9.

7. Tiono AB, Ouedraogo A, Bougouma EC, Diarra A, Konaté AT, Nébié I, et al. Placental malaria and low birth weight in pregnant women living in a rural area of Burkina Faso following the use of three preventive treatment regimens. Malar J. 2009; 8:1-8. doi:10.1186/1475-2875-8-224

8. National Population Commission (NPC) [Nigeria] and ICF International. Nigeria Demographic and Health Survey 2013 [Internet]. Abuja, Nigeria, and Rockville, Maryland, USA: NPC and ICF International; 2014. Available from:

http//:www.population.gov.ng/ndhs-data.

9. Multilateral Initiative on Malaria. Malaria : A Global Burden. 2010.

10. Kwadwo AK and Quashie N. Comparative efficacy of antimalarial drugs including ACTs in the treatment of uncomplicated malaria among children under 5 years in Ghana. Acta Trop. 2005; 95(3):194203.

11. Yeung S, Pongtavornpinyo W, Hastings IM, Mills AJ and White NJ. Antimalarial drug resistance, artemisinin-based combination therapy, and the contribution of modeling to elucidating policy choices. Am J Trop Med Hyg. 2004; 71(Suppl 2):179-86.

12. Federal Ministry of Health, National Malaria and Vector Control Division Abuja-Nigeria. National Antimalarial Treatment Policy. 2005.

13. Mace KE, Mwandama D, Jafali J, Luka M, Filler SJ, Sande J, et al. Adherence to Treatment with Artemether- Lumefantrine for Uncomplicated Malaria in Rural Malawi. Clin Infect Dis. 2011; 53(8):772-779. doi:10.1093/cid/cir498

14. Kiguli J, Namiiro P, Musabe JOY, Kyomugisha A and Guthmann J. Adherence to a six-dose regimen of artemether-lumefantrine for treatment of uncomplicated plasmodium falciparum malaria in Uganda. Am J Trop Med Hyg. 2004; 71(5):525-30.

15. Kachur SP, Khatib RA, Kaizer E, Fox SS, Abdulla $\mathrm{SM}$ and Bloland PB. Adherence to antimalarial combination therapy with sulfadoxine-pyrimethamine and artesunate in rural Tanzania. Am J Trop Med Hyg. 2004; 71(6):715-22.

16. White NJ and Shunmay Y. How do patients use antimalarial drugs? A review of the evidence. Trop Med Int Heal. 2005; 8: 133-9.

17. Meremikwu M, Okomo U, Nwachukwu C, Oyo-ita A, Eke-njoku J, Okebe J, et al. Antimalarial drug prescribing practice in private and public health facilities in South-east Nigeria: a descriptive study. Malar J. 2007;6: 55. doi:10.1186/1475-2875-6-55

18. Riley C, Dellicour S, Ouma P, Kioko U, Kuile FO, Omar A, et al. Knowledge and Adherence to the National Guidelines for Malaria Case Management in Pregnancy among Healthcare Providers and Drug Outlet Dispensers in Rural, Western Kenya. PLoS One. 2016:1-18.

doi:10.1371/journal.pone. 0145616

19. Wasunna B, Zurovac D, Goodman CA and Snow RW. Why don't health workers prescribe ACT? A qualitative study of factors affecting the prescription of artemether-lumefantrine. Malar J. 2008; 7: 29. doi:10.1186/1475-2875-7-29

20. Bell DJ, Wootton D, Mukaka M, Montgomery J, Kayange N, Chimpeni P, et al. Effectiveness of artemether-lumefantrine, chlorproguanil-dapsone or sulphadoxine-pyrimethamine in the treatment of uncomplicated malaria in Malawi. Malar J. 2009; 8:204. doi:10.1186/1475-2875-8-204

21. Dodoo ANO, Fogg C, Asiimwe A, Nartey ET, Kodua A, Tenkorang O, et al. Pattern of drug utilization for treatment of uncomplicated malaria in urban Ghana following national treatment policy 
change to artemisinin-combination therapy. Malar J. 2009;8:2. doi:10.1186/1475-2875-8-2

22. Odey F, Esu E, Effa E, Udoh E, Oduwole O, Chibuzo M, et al. Management of severe malaria in children under five years of age in private and public health facilities in Cross Rivers State, Southeastern Nigeria: an audit of current practices. Clin Audit. 2013; 3(5):43-8.

23. Ezeudu CE, Ebenebe JC, Chukwuka JO, Ugochukwu EF, Amilo GI and Okorie OI. Malaria parasitaemia among febrile under-five children at Nnamdi Azikiwe University Teaching Hospital, Nnewi, South-East, Nigeria. Niger J Med. 2016; 25(2):113-118.

24. Cockburn R, Newton PN, Agyarko EK, Akunyili D and White NJ. The global threat of counterfeit drugs: Why industry and govern ments must communicate the dangers. PLoS Med. 2005; 2:e100.

25. Price RN, Dorsey G, Ashley EA, Barnes KI, Baird $\mathrm{K}$, Alessandro U, et al. World Antimalarial Resistance Network I : Clinical efficacy of antimalarial drugs. Malar J. 2007; 6:119. doi:10.1186/14752875-6-119

26. Souares A, Lalou R, Sene I, Sow D and Le Hesran JY. Adherence and effectiveness of drug combination in curative treatment among children suffering uncomplicated malaria in rural Senegal. Trans $R$ Soc Trop Med Hyg. 2008; 102(8):751-8.

27. Gerstl S, Dunkley S, Mukhtar A, Baker S and Maikere J. Successful introduction of artesunate combination therapy is not enough to fight malaria: results from an adherence study in Sierra Leone. Trans R Soc Trop Med Hyg. 2010; 104(5):328-35.

28. World Health Organization. The use of antimalarial drugs : Report of a WHO informal consultation 1317 November 2000. Geneva; 2001.

29. Barnes KI, Durrheim DN, Little F, Jackson A, Mehta U, Allen E, et al. Effect of Artemether-Lumefantrine Policy and Improved Vector Control on Malaria Burden in KwaZulu - Natal, South Africa. Malar J. 2005; 2(11):e330.

doi:10.1371/journal.pmed.0020330

Copyright (C) The Author(s). This is an Open Access article under the CC BY license. 